\title{
KUALITAS PELAYANAN KESEHATAN PASIEN PESERTA JKN-KIS DI BAGIAN RAWAT JALAN RSUD SYEKH YUSUF KABUPATEN GOWA PERSPEKTIF PELANGGAN INTERNAL DAN EKSTERNAL
}

\section{QUALITY OF PATIENT SERVICE OF JKN-KIS PARTICIPANTS IN OUTPATIENT DIVISION OF SYEKH YUSUF DISTRICT HOSPITAL GOWA PERSPECTIVE OF INTERNAL AND EXTERNAL CUSTOMERS}

\author{
Zilfadhilah Arranury ${ }^{1}, H$. Indar ${ }^{2}$, Ridwan M Thaha ${ }^{3}$ \\ ${ }^{1}$ Program Pascasarjana, Departmen Administrasi dan Kebijakan Kesehatan, Fakultas \\ Kesehatan Masyarakat, Universitas Hasanuddin \\ ${ }^{2}$ Departmen Administrasi dan Kebijakan Kesehatan, Fakultas Kesehatan Masyarakat, \\ Universitas Hasanuddin \\ ${ }^{3}$ Departemen Promosi Kesehatan dan Ilmu Perilaku, Fakultas Kesehatan Masyarakat, \\ Universitas Hasanuddin
}

\begin{abstract}
Alamat Korespondensi : Zilfadhilah Arranury, Fakultas Kesehatan Masyarakat, Universitas Hasanuddin, Makassar, 90242, HP: +6285240705413, Email: iylhamec@gmail.com
\end{abstract}

\begin{abstract}
Abstrak
Kualitas pelayanan pada dasarnya terkait dengan pelayanan yang baik, yaitu suatu sikap atau cara karyawan dalam melayani pelanggan atau masyarakat secara memuaskan. Tujuan penelitian ini adalah untuk mengetahui hubungan kualitas pelayanan kesehatan terhadap kepuasan pasien peserta JKN-KIS di bagian rawat jalan RSUD Syekh Yusuf Kabupaten Gowa dari perspektif pelanggan eksternal. Jenis penelitan yang digunakan adalah penelitian kuantitatif dengan pendekatan cross sectional study. Populasi dalam penelitian ini adalah pasien peserta JKN-KIS di bagian rawat jalan sebanyak 54.489 pasien. Teknik pengambilan sampel pada penelitian ini menggunakan teknik accidental sampling dengan besar sampel 369 orang. Analisis data yang dilakukan adalah univariat dan bivariat dengan uji chi square. Hasil uji chi-square menunjukkan bahwa ada hubungan kualitas pelayanan variabel kehandalan $(\mathrm{p}=0,032)$, jaminan $(0,000)$, bukti fisik $(0,027)$, empati $(0,001)$, dan daya tanggap $(0,000)$ terhadap kepuasan pasien di bagian rawat jalan RSUD Syekh Yusuf Kabupaten Gowa Tahun 2018. Diharapkan semua variabel kualitas pelayanan yang berhubungan dengan kepuasan pasien lebih diperhatikan dan dijadikan tolak ukur dalam peningkatan kualitas pelayanan di rumah sakit.
\end{abstract}

Kata kunci: kualitas pelayanan, kepuasan pasien, pasien peserta JKN-KIS

\begin{abstract}
Quality of service is basically related to good service, that is an attitude or way of employee in serving customer or society satisfactorily. The purpose of this study is to determine the relationship of health service quality to patient satisfaction of JKN-KIS participants in the outpatient of Syekh Yusuf District Hospital of Gowa from the perspective of external customers. Type of research used is quantitative research with cross sectional study approach. The population in this study were JKN-KIS patients in the outpatient section of 54,489 patients. Sampling technique in this research use accidental sampling technique with 369 sample size. Data analysis performed was univariate and bivariate with chi square test. The result of chi-square test shows that there are correlation of service quality of reliability variable $(p=0,032)$, assurance $(0,000)$, physical proof $(0,027)$, empathy (0,001), and responsiveness (0,000) to patient satisfaction at outpatient of Syekh Hospital Yusuf Kabupaten Gowa Year 2018. It is expected that all variables of service quality associated with patient satisfaction is more attention and serve as a benchmark in improving service quality in hospitals.
\end{abstract}

Keywords: service quality, patient satisfaction, patient participant JKN-KIS 


\section{PENDAHULUAN}

Pelayanan kesehatan adalah hak asasi manusia yang harus dipenuhi oleh pemerintah dan setiap orang berhak mendapatkan pelayanan kesehatan. WHO telah berkomitmen untuk mengembangkan suatu sistem kesehatan yang dikenal dengan Universal Health Coverage (UHC) untuk memastikan bahwa semua orang dapat menggunakan layanan kesehatan yang mereka butuhkan dan juga memastikan bahwa penggunaan layanan ini tidak membuat pengguna merasa kesulitan dalam hal finansial (WHO, 2013).

Hal ini juga ditegaskan dalam Undang-Undang No.36 Tahun 2009 bahwa pemerintah bertanggung jawab atas ketersediaan segala bentuk upaya kesehatan yang bermutu, efisien, dan terjangkau. Oleh karena itu, pemerintah telah mengambil kebijakan strategis untuk memberlakukan Jaminan Kesehatan Nasional (JKN) - Kartu Indonesia Sehat (KIS) yang diselenggarakan oleh Badan Penyelenggara Jaminan Sosial (BPJS) agar dapat memenuhi kebutuhan dasar hidup yang layak dan meningkatkan martabatnya menuju terwujudnya masyarakat Indonesia yang sejahtera, adil dan makmur.

Pasien atau pelanggan eksternal menuntut pelayanan yang berkualitas tidak hanya menyangkut kesembuhan dari penyakit secara fisik atau meningkatkan derajat kesehatannya, tetapi juga menyangkut kepuasan terhadap sikap, selalu tersedianya sarana dan prasarana yang memadai dan lingkungan fisik yang dapat memberikan kenyamanan (Muninjaya, 2011). Kepuasan pasien tergantung pada kualitas pelayanan yang diberikan. Semakin tinggi kualitas pelayanan yang diberikan, maka akan menunjukkan kepuasan pasien terhadap layanan yang kemudian akan meningkatkan loyalitas pasien terhadap pemberi pelayanan (Markovic dkk, 2014). Pengukuran kualitas pelayanan salah satunya dapat dilakukan dengan menggunakan metode Service Quality Parasuraman dkk (2005) yaitu kehandalan (reliability), jaminan (assurance), bukti langsung/ berwujud (tangible), empati (empathy), daya tanggap (Responsiveness). Sejalan dengan penelitian yang dilakukan oleh Belaid dkk (2015) dengan menggunakan dimensi service quality oleh Parasuraman menunjukkan bahwa ada hubungan yang signifikan antara kualitas layanan secara keseluruhan dengan kepuasan pasien.

Salah satu institusi pelayanan kesehatan yang menyediakan fasilitas pelayanan kesehatan kepada masyarakat pengguna JKN-KIS adalah Rumah Sakit Umum Daerah (RSUD) Syekh Yusuf Kabupaten Gowa. RSUD Syekh Yusuf Kabupaten Gowa adalah rumah sakit 
dengan klasifikasi B Non Pendidikan milik pemerintah daerah Kabupaten Gowa yang merupakan rumah sakit rujukan bagian selatan yang telah terakreditasi paripurna oleh Tim Komisi Akreditasi Rumah Sakit (KARS) pada tahun 2017 yang artinya rumah sakit sudah diakui mempunyai pelayanan bermutu dengan nilai minimal $80 \%$ untuk setiap 15 standar akreditasi, salah satunya yaitu pelayanan kepada pasien (RSUD Syekh Yusuf, 2017)

Observasi awal yang dilakukan oleh peneliti pada bulan Januari 2018 terhadap peserta JKN-KIS di bagian rawat jalan RSUD Syekh Yusuf didapati yang menjadi keluhan pasien adalah ruang tunggu yang tidak memadai, petugas yang kurang ramah, tenaga medis yang datang terlambat, dan waktu tunggu pasien lebih dari 60 menit untuk mendapatkan pelayanan kesehatan yaitu mulai dari kedatangan pasien untuk mengambil nomor antrian sampai mendapatkan pemeriksaan oleh dokter, hal ini juga diperkuat oleh staf bagian pengaduan yang menyatakan bahwa banyaknya pasien yang mengeluhkan hal tersebut. Standar pelayanan minimal di rawat jalan mulai pasien datang sampai mendapatkan pelayanan oleh dokter berdasar Kemenkes Nomor 129/Menkes/SK/II/2008 ialah kurang atau sama dengan 60 menit (Kemenkes RI, 2008). Peraturan Presiden No. 12 Tahun 2013 Pasal 42 Tentang Jaminan Kesehatan telah menyatakan bahwa pelayanan kesehatan kepada Peserta Jaminan Kesehatan harus memperhatikan mutu pelayanan (Perpres RI, 2013). Tujuan penelitian ini adalah untuk mengetahui hubungan kualitas pelayanan kesehatan terhadap kepuasan pasien peserta JKN-KIS di bagian rawat jalan RSUD Syekh Yusuf Kabupaten Gowa dari perspektif pelanggan eksternal.

\section{BAHAN DAN METODE}

\section{Lokasi dan Rancangan Penelitian}

Penelitian ini dilakukan di Rumah Sakit Umum Daerah Syekh Yusuf Kabupaten Gowa. Jenis penelitian yang digunakan dalam penelitian ini adalah penelitian kuantitatif dengan pendekatan cross sectional study.

\section{Populasi dan Sampel}

Populasi adalah seluruh pasien peserta JKN-KIS di bagian rawat jalan Rumah Sakit Umum Daerah Syekh Yusuf Kabupaten Gowa Tahun 2018. Besar sampel dalam penelitian ini adalah sebanyak 369 orang yang diperoleh dengan menggunakan metode accidental sampling.

\section{Metode Pengumpulan Data}

Pengumpulan data dilakukan dengan cara membagikan kuesioner kepada responden yang berisi pertanyaan-pertanyaan. Data sekunder diperoleh dari dokumendokumen RSUD Syekh Yusuf Kabupaten Gowa. 
Analisis Data

Analisis data yang digunakan dalam penelitian ini adalah analisis univariat dan analisis bivariat. Analisis univariat dilakukan untuk melihat karakteristik responden yang disajikan dengan tabel distribusi frekuensi. Analisis bivariat dilakukan untuk mengetahui hubungan masing-masing variabel independen dan variabel dependen dengan menggunakan uji chi square.

\section{HASIL}

\section{Karakteristik Responden}

Tabel 1 menunjukkan karakteristik responden berdasarkan umur, jenis kelamin, pendidikan, dan pekerjaan. Berdasarkan karakteristik umur, jumlah responden yang paling banyak berada pada kelompok umur 36-50 tahun yaitu sebanyak 149 orang (40.4\%), sedangkan jumlah responden yang paling sedikit berada pada kelompok umur 20-35 tahun yaitu 95 orang (25.7\%). Berdasarkan jenis kelamin jumlah responden yang paling banyak adalah jenis kelamin perempuan yaitu 304 orang $(82.4 \%)$, sedangkan jenis kelamin laki-laki yaitu 65 orang (17.6\%). Berdasarkan pendidikan terakhir responden yang paling banyak adalah dengan tingkat pendidikan SMA/Sederajat yaitu 124 orang $(33.6 \%)$, sedangkan responden yang paling sedikit adalah yang tidak pernah mengenyam bangku sekolah yaitu 4 orang (1.1\%). Berdasarkan pekerjaan menunjukkan bahwa responden yang paling banyak berkerja sebagai Ibu Rumah Tangga yaitu 244 orang (66.1\%) dan yang paling sedikit adalah mahasiswa/siswa yaitu 3 orang $(0.8 \%)$.

Tabel 2 menunjukkan bahwa jumlah responden yang menyatakan baik terhadap variabel kehandalan (reliability) yaitu sebanyak $327(88.6 \%)$ orang dan kurang baik sebanyak 42 (11.4\%) orang. Jumlah responden yang menyatakan baik terhadap variabel jaminan (assurance) sebanyak 351 (95.1\%) orang sedangkan kurang baik adalah 18 (4.9\%) orang. Jumlah responden yang menyatakan baik terhadap variabel bukti fisik (tangible) adalah 337 (91.3\%) orang, sedangkan kurang baik sebanyak $32(8.7 \%)$ orang. Jumlah responden yang menyatakan baik terhadap variabel empati (empathy) adalah 356 (96.5\%) orang, sedangkan kurang baik sebanyak $13 \quad(3.5 \%)$ orang. Jumlah responden yang menyatakan baik terhadap variabel daya tanggap (responsiveness) adalah 313 (84.8\%) orang, sedangkan kurang baik sebanyak 56 (15.2\%) orang.

\section{Analisis Bivariat}




\begin{tabular}{|c|c|c|c|}
\hline \multicolumn{4}{|c|}{ Tabel 1. Karakteristik Responden } \\
\hline \multirow{2}{*}{ Karakteristik Responden } & \multirow{2}{*}{ Kategori } & \multicolumn{2}{|c|}{ Frekuensi } \\
\hline & & $\mathrm{N}$ & $\%$ \\
\hline \multirow{4}{*}{ Umur } & 20-35 Tahun & 95 & 25.7 \\
\hline & 36-50 Tahun & 149 & 40.4 \\
\hline & $>50$ Tahun & 125 & 33.9 \\
\hline & Total & 369 & 100 \\
\hline \multirow{3}{*}{ Jenis Kelamin } & Laki-laki & 65 & 17.6 \\
\hline & Perempuan & 304 & 82.4 \\
\hline & Total & 369 & 100 \\
\hline \multirow{6}{*}{ Pendidikan } & Tidak Sekolah & 4 & 1.1 \\
\hline & SD/Sederajat & 86 & 23.3 \\
\hline & SMP/Sederajat & 69 & 18.7 \\
\hline & SMA/Sederajat & 124 & 33.6 \\
\hline & Akademik/PT & 86 & 23.3 \\
\hline & Total & 369 & 100 \\
\hline \multirow{10}{*}{ Pekerjaan } & Tidak Bekerja & 7 & 1.9 \\
\hline & Mahasiswa/Siswa & 3 & 0.8 \\
\hline & IRT & 244 & 66.1 \\
\hline & PNS/TNI/Polri & 43 & 11.7 \\
\hline & Pegawai Swasta & 6 & 1.6 \\
\hline & Wiraswasta & 19 & 5.1 \\
\hline & Petani/Nelayan & 9 & 2.4 \\
\hline & Pensiunan PNS & 23 & 6.2 \\
\hline & Lain-lain & 15 & 4.1 \\
\hline & Total & 369 & 100 \\
\hline
\end{tabular}

Sumber: Data Primer Tahun 2018

Tabel 2. Analisis Univariat Distribusi Responden Berdasarkan Variabel Kehandalan, Jaminan, Bukti Fisik, Empati, dan Daya Tanggap di Bagian Rawat Jalan RSUD Syekh Yusuf Kabupaten Gowa Tahun 2018

\begin{tabular}{lrc}
\hline \multicolumn{1}{c}{ Variabel } & n & \% \\
\hline Kehandalan & 327 & 88.6 \\
Baik & 42 & 11.4 \\
Kurang Baik & 369 & 100 \\
Total & & \\
Jaminan & 351 & 95.1 \\
Baik & 18 & 4.9 \\
Kurang Baik & 369 & 100 \\
Total & & \\
Bukti Fisik & 337 & 91.3 \\
Baik & 32 & 8.7 \\
Kurang Baik & 369 & 100 \\
Total & & \\
Empati & 356 & 96.5 \\
Baik & 13 & 3.5 \\
Kurang Baik & 369 & 100 \\
Total & & \\
Daya Tanggap & 313 & 84.8 \\
Baik & 56 & 15.2 \\
Kurang Baik & 369 & 100 \\
Total & & \\
& &
\end{tabular}

Sumber: Data Primer Tahun 2018 


\section{Analisis Bivariat}

Tabel 3 menunjukkan bahwa dari 369 responden yang menilai kehandalan (reliability) baik dan puas dengan kualitas pelayanan yang dirasakan yaitu sebanyak $280(85.6 \%)$ orang dan yang menyatakan kurang puas yaitu 47 (14.4\%) orang. Sedangkan responden yang menyatakan bahwa kehandalan (reliability) kurang baik tetapi merasa puas dengan kualitas pelayanan yang dirasakan yaitu 30 (71.4\%) orang dan yang menyatakan kurang baik dan kurang puas yaitu 12 (28.6\%) orang. Hasil uji statistik diperoleh nilai $\mathrm{p}=0.032$, karena nilai $\mathrm{p}<\alpha=0.032<0.05$ maka ada hubungan antara variabel kehandalan (reliability) dengan kepuasan pasien.

Berdasarkan variabel jaminan menunjukkan bahwa dari 369 responden yang menilai jaminan (assurance) baik dan puas terhadap kualitas pelayanan yang dirasakan yaitu sebanyak 303 (86.3\%) orang dan yang menilai kurang puas yaitu $48(13.7 \%)$ orang. Sedangkan responden yang menilai kurang baik tetapi merasa puas terhadap kualitas pelayanan yang dirasakan yaitu 7 (38.9\%) orang dan yang menilai kurang baik dan kurang puas yaitu $11(61.1 \%)$ orang. Hasil uji statistik dengan menggunakan fisher's exact text diperoleh nilai $\mathrm{P}=0.000$, karena nilai $\mathrm{p}<\alpha$ $=0.000<0.05$ maka ada hubungan antara variabel jaminan (assurance) dengan kepuasan pasien.
Berdasarkan variabel bukti fisik menunjukkan bahwa dari 369 responden yang menilai bukti fisik (tangible) baik dan puas dengan kualitas pelayanan yang dirasakan yaitu sebanyak 288 (85.5\%) orang dan yang menilai kurang puas yaitu $49(14.5 \%)$ orang. Sedangkan responden yang menilai kurang baik tetapi merasa puas terhadap kualitas pelayanan yaitu 22 (68.8\%) orang dan responden yang menilai kurang baik dan kurang puas terhadap kualitas pelayanan yang dirasakan yaitu 10 (31.3\%) orang. Hasil uji statistik diperoleh nilai $\mathrm{p}=0.027$, karena nilai $\mathrm{p}<\alpha=$ $0.027<0.05$ maka ada hubungan antara bukti fisik (tangible) dengan kepuasan pasien.

Berdasarkan variabel empati menunjukkan bahwa dari 369 responden yang menilai empati (empathy) baik dan puas terhadap kualitas pelayanan yang dirasakan yaitu sebanyak 304 (85.4\%) orang dan yang menilai kurang puas yaitu $52(14.6 \%)$ orang. Sedangkan responden yang menilai empati (empathy) kurang baik dan kurang puas terhadap kualitas pelayanan yang dirasakan yaitu 7 (53.8) orang dan yang menilai kurang baik tetapi merasa puas yaitu $6(46.2 \%)$ orang. Hasil uji statistik dengan menggunakan fisher's exact test diperoleh nilai $\mathrm{p}=0.001$, karena nilai $\mathrm{p}<\alpha=0.001<0.05$ maka ada hubungan antara variabel empati (empathy) dengan kepuasan pasien. 
Berdasarkan variabel daya tanggap menunjukkan bahwa dari 369 responden yang menilai baik dan puas terhadap kualitas pelayanan yang dirasakan yaitu sebanyak $273(87.2 \%)$ orang dan yang menilai kurang puas yaitu 40 (12.8\%) orang. Sedangkan responden yang menilai daya tanggap kurang baik tetapi merasa puas terhadap kualitas pelayanan yaitu 37 $(66.1 \%)$ orang dan responden yang menilai kurang baik dan kurang puas yaitu 19 (33.9\%) orang. Hasil uji statistik diperoleh nilai $\mathrm{p}=0.000$, karena nilai $\mathrm{p}<\alpha=0.000<$ 0.05 maka ada hubungan antara daya tanggap (responsiveness) dengan kepuasan pasien.

Tabel 3. Analisis Bivariat Hubungan Kualitas Pelayanan Variabel Kehandalan,

Jaminan, Bukti Fisik, Empati, dan Daya Tanggap Terhadap Kepuasan Pasien Peserta JKN- KIS di Bagian Rawat Jalan RSUD Syekh Yusuf Kabupaten Gowa Tahun 2018

\begin{tabular}{|c|c|c|c|c|c|c|c|}
\hline \multirow{3}{*}{ Variabel } & \multicolumn{4}{|c|}{ Kepuasan Pasien } & \multirow{2}{*}{\multicolumn{2}{|c|}{ Total }} & \multirow{3}{*}{$\begin{array}{c}\text { Hasil Uji } \\
\text { Statistik }\end{array}$} \\
\hline & \multicolumn{2}{|c|}{ Puas } & \multicolumn{2}{|c|}{ Kurang Puas } & & & \\
\hline & $\mathrm{N}$ & $\%$ & $\mathrm{n}$ & $\%$ & $\mathrm{n}$ & $\%$ & \\
\hline \multicolumn{8}{|l|}{ Kehandalan } \\
\hline Baik & 280 & 85.6 & 47 & 14.4 & 327 & 100 & $P=0.032$ \\
\hline Kurang Baik & 30 & 71.4 & 12 & 28.6 & 42 & 100 & \\
\hline \multicolumn{8}{|l|}{ Jaminan } \\
\hline Baik & 303 & 86.3 & 48 & 13.7 & 351 & 100 & $P=0.000$ \\
\hline Kurang Baik & 7 & 38.9 & 11 & 61.1 & 18 & 100 & \\
\hline \multicolumn{8}{|l|}{ Bukti Fisik } \\
\hline Baik & 288 & 85.5 & 49 & 14.5 & 337 & 100 & $P=0.027$ \\
\hline Kurang Baik & 22 & 68.8 & 10 & 31.3 & 32 & 100 & \\
\hline \multicolumn{8}{|l|}{ Empati } \\
\hline Baik & 304 & 85.4 & 52 & 14.6 & 356 & 100 & $P=0.001$ \\
\hline Kurang Baik & 6 & 46.2 & 7 & 53.8 & 13 & 100 & \\
\hline \multicolumn{8}{|l|}{ Daya Tanggap } \\
\hline Baik & 273 & 87.2 & 40 & 12.8 & 313 & 100 & $P=0.000$ \\
\hline Kurang Baik & 37 & 66.1 & 19 & 33.9 & 56 & 100 & \\
\hline
\end{tabular}

Sumber: Data Primer Tahun 2018

\section{PEMBAHASAN}

Hasil penelitian ini menunjukkan bahwa kualitas pelayanan variabel kehandalan $(\mathrm{p}=0,032)$, jaminan $(\mathrm{p}=0,000)$, bukti fisik $(p=0,027)$, empati $(p=0,001)$, dan daya tanggap $(p=0,000)$ memiliki 
hubungan yang signifikan terhadap

kepuasan pasien di bagian rawat jalan

RSUD Syekh Yusuf Kabupaten Gowa

Tahun 2018.

Kehandalan

(Reliability)

merupakan perspektif pasien terhadap kemampuan petugas untuk memberikan pelayanan dengan tepat dan akurat (Pohan, 2012). Al-Damen (2017) menyatakan bahwa kehandalan (reliability) merupakan kemampuan untuk memberikan pelayanan kesehatan yang dijanjikan, dapat diandalkan dan akurat. Responden merasa puas terhadap kualitas pelayanan yang dirasakan tersebut karena dokter memeriksa pasien dengan sungguhsungguh dan perawat membantu dokter dengan baik dalam memberikan pelayanan kepada pasien sehingga responden merasa puas dengan pelayanan yang diberikan dokter dan perawat. Sedangkan pasien merasa kurang puas disebabkan oleh persepsi pasien terhadap pelayanan yang diberikan tidak sesuai dengan waktu yang dijanjikan oleh rumah sakit yaitu pelayanan di poliklinik dimulai pukul 09.00 pagi, namun yang terjadi di beberapa poliklinik waktu pelayanan dimulai pukul 9 lewat bahkan dimulai pukul 10 sehingga ada pasien yang tidak mendapatkan pelayanan oleh dokter karena jam pelayanan yang sudah habis. Hal ini disebabkan karena dokter harus melakukan aktifitas di bagian yang lain selain di rawat jalan.
Penelitian yang sama juga

dilakukan oleh Belaid dkk (2015) menyatakan bahwa ada hubungan yang signifikan antara kualitas pelayanan kesehatan dimensi kehandalan (reliability) dengan kepuasan pasien di Rumah Sakit Umum Bechar.

Jaminan (Assurance) merupakan perspektif pasien terhadap kemampuan petugas dalam meyakinkan pasien bahwa tindakan yang diberikan mampu mengatasi masalah pasien. Pasien mersa puas terhadap kualitas pelayanan yang dirasakan karena pasien merasa bahwa petugas kesehatan (dokter) di bagian rawat jalan RSUD Syekh Yusuf mampu memberikan kepercayaan/jaminan kepada pasien. Hal ini dirasakan pasien saat menerima pelayanan dari dokter dimana dokter memiliki kemampuan dan pengetahuan dalam menetapkan diagnosa penyakit dan mampu menjawab semua pertanyaan pasien dengan sabar dan meyakinkan.

Hasil penelitian ini sejalan dengan penelitian yang dilakukan oleh Kitapci dkk (2014) yang menyatakan bahwa ada hubungan antara jaminan (assurance) dengan kepuasan pasien di bagian rawat jalan Rumah Sakit Turki dengan nilai $\mathrm{p}$ $(0.000)<\alpha(0.05)$.

Bukti Fisik (tangible) merupakan perspektif pasien terhadap ruangan pelayanan dan kondisi peralatan di bagian rawat jalan RSUD Syekh Yusuf. Pasien merasa puas dengan fasilitas yang 
disediakan di bagian rawat jalan RSUD

Syekh Yusuf, karena ruang poliklinik yang bersih dan nyaman, peralatan yang digunakan selalu siap dan dalam keadaan bersih serta petugas kesehatan yang senantiasa berpenampilan rapi. Namun, fasilitas di ruang tunggu masih perlu untuk ditingkatkan karena kurang memadai seperti kursi di ruang tunggu tidak mencukupi jumlah pasien yang datang berkunjung sehingga terkadang ada pasien yang berdiri atau duduk di tangga untuk menunggu pelayanan petugas kesehatan, jumlah kipas angin yang kurang dan terkadang tidak difungsikan sehingga pasien merasa kepanasan.

Hal ini menunjukkan bahwa fasilitas fisik yang disediakan di bagian rawat jalan mempengaruhi tingkat kepuasan pasien. Semakin baik fasilitas fisiknya, semakin tinggi pula tingkat kepuasan pasien. Oleh karena itu, pihak rumah sakit harus lebih memperhatikan fasilitas yang digunakan oleh pasien agar pasien merasa nyaman saat datang untuk berobat. Hasil penelitian ini sejalan dengan penelitian yang pernah dilakukan oleh Belaid dkk (2015) yang menyatakan bahwa ada hubungan yang signifikan antara kualitas pelayanan kesehatan dimensi bukti fisik (tangible) terhadap kepuasan pasien di Rumah Sakit Umum Bechar.

Empati (empathy) merupakan perspektif pasien terhadap kemampuan petugas untuk memahami apa yang dirasakan oleh pasien. Empati (empathy) oleh pasien dikatakan baik karena pasien merasa bahwa petugas kesehatan (dokter) selalu menanyakan kabar dan keadaan pasien, bersedia mendengarkan keluhan pasien, dan tidak membeda-bedakan pasien JKN-KIS dengan pasien umum saat melakukan tindakan. Sedangkan pasien yang mengatakan empati (empathy) petugas kesehatan kurang baik disebabkan oleh persepsi beberapa pasien yang menilai pelayanan perawat yang kurang ramah saat melayani pasien.

Hal ini menunjukkan bahwa sikap petugas saat melayani pasien akan mempengaruhi tingkat kepuasan pasien. Semakin baik pelayanan yang diterima, maka pasien akan puas yang kemudian akan meningkatkan minat kembali dan akan merekomendasikannya kepada orang lain. Hasil penelitian ini sejalan dengan penelitian yang dilakukan oleh Kitapci dkk (2014) di industri pelayanan kesehatan yang menyebutkan bahwa ada hubungan yang signifikan antara variabel empati dengan kepuasan pelanggan.

Daya Tanggap (responsiveness) merupakan perspektif pasien terhadap kemampuan petugas dalam membantu menangani keluhan pasien. Responden menilai baik terhadap variabel daya tanggap karena merasa petugas kesehatan (dokter) dalam memberikan informasi pengobatan menggunakan bahasa yang 
jelas dan mudah dimengerti, petugas kesehatan dengan sabar mendengarkan keluhan pasien dan tidak menjadikannya sebagai beban. Sedangkan beberapa responden yang menilai kurang baik disebabkan oleh persepsi pasien mengenai waktu tunggu untuk mendapatkan pelayanan oleh dokter. Pasien merasa kurang puas dengan pelayanan rawat jalan RSUD Syekh yusuf karena pasien menunggu waktu yang lama bahkan sampai berjam-jam untuk mendapatkan pelayanan, hal ini disebabkan sistem informasi yang masih manual sehingga status atau berkas rekam medis pasien membutuhkan waktu cukup lama untuk sampai di poliklinik yang kemudian menumbuhkan persepsi pasien bahwa petugas kesehatan tidak cepat tanggap dalam memberikan pelayanan.

Hasil penelitian ini sejalan dengan penelitian yang pernah dilakukan oleh Belaid dkk (2015) yang menyatakan bahwa ada hubungan yang signifikan antara kualitas pelayanan kesehatan dimensi daya tanggap (responsiveness) terhadap kepuasan pasien di Rumah Sakit Umum Bechar.

\section{KESIMPULAN DAN SARAN}

Berdasarkan penelitian yang telah dilakukan menunjukkan bahwa ada hubungan kualitas pelayanan secara keseluruhan terhadap kepuasan pasien peserta JKN-KIS di bagian rawat jalan
RSUD Syekh Yusuf Gowa tahun 2018 dari perspektif pelanggan eksternal dengan menggunakan lima dimensi kualitas pelayanan (kehandalan, jaminan, bukti langsung, empati, dan daya tanggap). Diharapkan pihak rumah sakit untuk lebih memperhatikan jadwal dimulainya pelayanan oleh dokter agar dapat dilaksanakan sesuai dengan yang telah dijanjikan. Selain itu, perlu adanya peningkatan kuantitas dan kualitas fisik di bagian rawat jalan seperti pendingin ruangan, tempat duduk, serta peningkatan kualitas sistem informasi dari manual menjadi elektronik untuk memudahkan dalam proses pelayanan agar pasien tidak menunggu waktu yang lama untuk mendapatkan pelayanan.

\section{DAFTAR PUSTAKA}

Al-Damen, R. (2017). Health Care Service Quality and Its Impact on Patient Satisfaction "Case of Al-Bashir Hospital." International Journal of Business and Management, 12(9), p.136. Available at: http://ccsenet.org/journal/index.php/ijbm/a rticle/view/69370.

Belaid, H., Bouchenafa, A. \& Barich, A.B.D.E. (2015). the Quality of Health Services in Bechar Public Hospital Institution. , IV(2), pp.1-14.

Kemenkes RI. (2008). Standar Pelayanan Minimal Rumah Sakit. Jakarta

Kitapci, O., Akdogan, C. \& Dortyol, İ.T. (2014) - The Impact of Service Quality Dimensions on Patient Satisfaction, Repurchase Intentions and Word-of-Mouth Communication in the Public Healthcare Industry. Procedia - Social and Behavioral Sciences, 148, pp.161-169. Available at: http://linkinghub.elsevier.com/retrieve/pii/ S1877042814039342.

Markovic, S., Loncaric, D. \& Loncaric, D. 
(2014). Service quality and customer satisfaction in the health care industry Towards health tourism market. Tourism and Hospitality Management, 20(2), pp.155-170. Available at: http://www.scopus.com/inward/record.url? eid=2-s2.0-

84925866373\&partnerID=tZOtx3y1.

Muninjaya, A.A.G. (2011). Manajemen

Mutu Pelayanan Kesehatan. Jakarta:

Kedokteran EGC.

Parasuraman, A., Zeithaml, V.A. \& Malhotra, A. (2005). E-S-QUAL a multiple-item scale for assessing electronic service quality. Journal of Service Research, 7(3), pp.213-233.

Perpres RI. (2013). Peraturan Presiden Republik Indonesia Nomor 12 Tahun 2013 Tentang Jaminan Kesehatan. Jakarta

Pohan, I.S., 2012. Jaminan Mutu Layanan Kesehatan, Dasar-Dasar Pengertian dan Penerapan. Jakarta: EGC.

RSUD Syekh Yusuf. (2017). Profil RSUD Syekh Yusuf Kabupaten Gowa Tahun 2017. Kabupaten Gowa.

WHO. (2013). The world health report 2013: Research for universal health coverage. World Health Organization Press, p.146 